\title{
Influence of Conservation Programs on Amphibians using Seasonal Wetlands in the Prairie Pothole Region
}

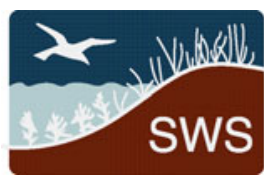

\author{
Caleb J. Balas • Ned H. Euliss Jr. • David M. Mushet
}

Received: 10 May 2011 / Accepted: 31 December 2011 / Published online: 9 February 2012

(C) The Author(s) 2012. This article is published with open access at Springerlink.com

\begin{abstract}
Extensive modification of upland habitats surrounding wetlands to facilitate agricultural production has negatively impacted amphibian communities in the Prairie Pothole Region of North America. In attempts to mitigate ecosystem damage associated with extensive landscape alteration, vast tracks of upland croplands have been returned to perennial vegetative cover (i.e., conservation grasslands) under a variety of U.S. Department of Agriculture programs. We evaluated the influence of these conservation grasslands on amphibian occupancy of seasonal wetlands in the Prairie Pothole Region. Using automated call surveys, aquatic funnel traps, and visual encounter surveys, we detected eight amphibian species using wetlands within three land-use categories (farmed, conservation grasslands, and native prairie grasslands) during the summers of 2005 and 2006. Seasonal wetlands within farmlands were used less frequently by amphibians than those within conservation and native prairie grasslands, and wetlands within conservation grasslands were used less frequently than those within native prairie grasslands by all species and life-stages we successfully modeled. Our results suggest that, while not occupied as frequently as wetlands within native prairie, wetlands within conservation grasslands provide important habitat for maintaining amphibian biodiversity in the Prairie Pothole Region.
\end{abstract}

\footnotetext{
C. J. Balas · N. H. Euliss Jr. $(\bowtie) \cdot$ D. M. Mushet

U.S. Geological Survey,

Northern Prairie Wildlife Research Center,

871137 Street SE,

Jamestown, ND 58401, USA

e-mail: ceuliss@usgs.gov

Present Address:

C. J. Balas

2052 Havana Street,

Aurora, CO 80010, USA
}

Keywords Amphibians · Detection probability - Glaciated plains · Land use · Minnesota · North Dakota · Occupancy · Seasonal wetlands

\section{Introduction}

Globally, amphibian population declines, range constrictions, and extinctions are a result of numerous causal factors and their synergistic relationships (Houlahan et al. 2000; Alford et al. 2001). However, land-use (Lannoo 1998) and global climate change may pose the greatest threat, especially for large species with small or fragmented ranges in areas characterized by extreme habitat loss and marked inter-annual climate variability (Sodhi et al. 2008). Soils in the Prairie Pothole Region (PPR) of North America are productive and the area has been highly developed to accommodate modern agriculture (Knutson and Euliss 2001). Land use has fragmented historical amphibian ranges (Lehtinen et al. 1999), and socioeconomic factors related to increased food, fiber, and energy needs likely exacerbate habitat fragmentation for amphibians and other wildlife. Additionally, the PPR has a dynamic interannual climate cycle where droughts are often followed by equally extreme periods of abundant precipitation (Winter and Rosenberry 1998). Global climate change projections for the PPR suggest greater variation in seasonal and inter-annual climate precipitation patterns in the future (Houghton et al. 2001; Tao et al. 2003; Field et al. 2007).

In the PPR, the primary land-use change has been the conversion of native habitats to croplands through tillage of uplands and drainage of wetlands. Approximately half of the wetlands in the PPR have been drained (Tiner 1984; Dahl 1990 ) and $34 \%$ of the native upland habitats have been converted to cropland (Euliss et al. 2006). Wetland drainage has had an especially negative impact on amphibians in the 
region; Lannoo et al. (1994) estimated a 99\% decline in northern IA's northern leopard frog (Lithobates pipiens) population since the early 1900's due exclusively to wetland drainage. Extensive road networks associated with the conversion of native habitats to cropland have also affected wetlands by altering historic sheet flow patterns (Kantrud and Newton 1996).

The Conservation Reserve Program (CRP) and the Wetlands Reserve Program (WRP) are administered by the U.S. Department of Agriculture's Farm Service Agency and Natural Resources Conservation Service, respectively. Together, these two programs include nearly 2,200,000 ha of wetland and grassland habitats in the PPR (Gleason et al. 2008). In most cases, CRP and WRP projects return the surrounding upland watersheds of wetlands to some form of perennial cover, a critical step to re-establishing ecosystem processes (Zedler 1996; Pechmann et al. 2001). While CRP and WRP undoubtedly benefit a myriad of ecosystem services (e.g. carbon sequestration, flood water attenuation, sediment and nutrient reduction, and bird habitat) (Gleason et al. 2008), their influence on amphibians is poorly understood. We hypothesized that these two U.S. Department of Agriculture conservation programs have augmented amphibian habitat in the PPR by an unknown extent. Our objectives were to 1) determine amphibian occupancy of seasonal wetlands within conservation program lands and 2) compare amphibian occupancy of these conservation wetlands to occupancy of similar wetlands within farmed lands and native prairie grasslands.

\section{Methods}

Study Area

We conducted our study during the summers of 2005 and 2006 in the Glaciated Plains physiographic region of the U. S. portion of the PPR (Fig. 1). The Glaciated Plains is a relatively flat, extensively developed, agricultural landscape that includes numerous wetlands (Bluemle 2000). The Glaciated Plains has a northwest to southeast gradient in climate and land use (i.e., the cooler and drier northwest is better suited to small grain production whereas the warmer and wetter southeast is better suited for row crops). Further, composition of amphibian communities also varies over the natural climate gradient. Nine amphibian species are found in the northwest portion of the Glaciated Plains whereas 15 species are found in the southeast (Oldfield and Moriarty 1994; Conant and Collins 1998; Amphibian Research and Monitoring Initiative 2007). We established study sites in three locations across the Glaciated Plains to account for the spatial gradients in climate, land-use, and amphibian species richness. Study sites were located near Devils Lake, ND; Fergus Falls, MN; and Spirit Lake, IA (Fig. 1). We limited our evaluation to seasonal wetlands. Seasonal wetlands are frequently surrounded by perennial cover established under CRP or WRP, and they support diverse amphibian communities (Kantrud and Newton 1996; Fischer et al. 1999). Our study sites were drawn from a random sample of seasonal wetlands stratified by Gleason
Fig. 1 The Prairie Pothole Region of the United States (heavy black line), the four physiographic regions, and three study site locations (white circles)

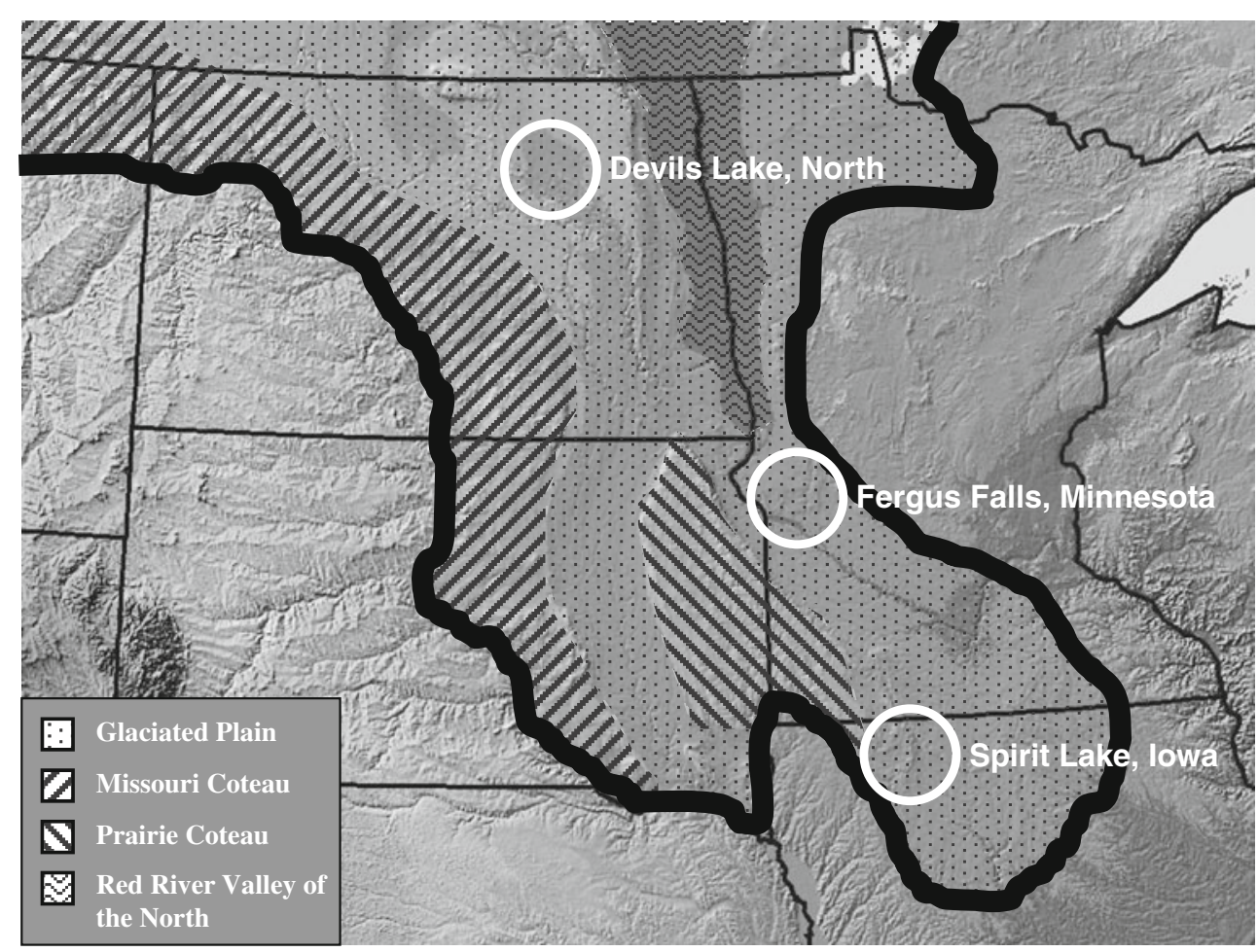


et al. (2008). We selected four wetlands from each of three land-use categories (i.e., farmed, conservation grasslands, native prairie grasslands) within each of the three study areas for a total of 36 wetlands. We defined farmed wetlands as wetlands that had been drained with open ditches or tiles, were in agricultural production during our study, and had adjacent uplands that never been enrolled in a conservation program. All conservation wetlands were within a site that had been enrolled in a conservation program no less than 10 years prior to our study, were hydrologically restored by diking or plugging of open ditches or destruction of buried tile drains, and had catchment basins that had been reseeded to perennial grassland. Wetlands within native prairie catchments had never been drained nor had their basins ever been cultivated. Selected wetlands ranged in size from 0.4 to 0.8 ha.

\section{Data Collection}

Ten species of amphibians are known to use seasonal wetlands in the study locations (Table 1); we sampled all species and life stages of amphibians in our study. In our surveys and analyses, we combined boreal chorus frogs (Pseudacris maculata) with western chorus frogs (Pseudacris triseriata), and Cope's gray treefrogs (Hyla chrysoscelis) with eastern gray treefrogs (Hyla versicolor) because they are physically indistinguishable in the field (Conant and Collins 1998). Similarly, we combined American toad (Anaxyrus americanus) and Canadian toad (Anaxyrus hemiophrys) larvae because they are difficult to tell apart in the field (Conant and Collins 1998). Hence, we considered six adult species, two adult morphospecies, five larval species, and three larval morphospecies (hereafter all referred to as species) in our study (Table 1).

The eight amphibian species we evaluated have life stages that use aquatic and terrestrial habitats. Habitat use varies temporally among adults and larvae which made it difficult to detect both life stages occupying a wetland (Heyer et al. 1994). To increase our probability of detecting all species and life stages, we used several techniques that included automated call surveys, aquatic funnel traps, and visual encounter surveys (Halliday 2006). Study wetland visits were conducted biweekly in 2005 and 2006 at each wetland beginning the third week of May and ending the third week of June (i.e. wetlands were visited 3 times per year). All survey techniques were used during each visit unless a wetland was dry, in which case we only used visual encounter and call surveys.

We recorded anuran vocalizations using analog recorders (Marantz ${ }^{\circledR}$ model PMD101, Aurora, IL) equipped with omnidirectional microphones (Audio-Technica ${ }^{\circledR}$ model AT804, Stow, OH) (Bowers 1998). Units were equipped with programmable event recorders (Artisan ${ }^{\circledR}$ model 4950, Parsippany, NJ) set to record for one night during each sampling period. Recorders were set to run for 5 min intervals every $2 \mathrm{~h}$ between 2230 and $0435 \mathrm{~h}$. We placed a recorder at the north end of each wetland between the center of the wetland and the wet meadow zone (Stewart and Kantrud 1971). Recordings were interpreted by two independent technicians to minimize listener bias (Heyer et al. 1994); vocalizations were identified

Table 1 Amphibian species potentially inhabiting study sites (i.e., study site falls within known range of a species) in North Dakota,

1998; Fisher et al. 1999). Potential inhabitants (P) and actual detections in 2005 (D1) and 2006 (D2) are indicated with an asterisk.

Minnesota, and Iowa (Oldfield and Moriarty 1994; Conant and Collins

\begin{tabular}{|c|c|c|c|c|c|c|c|c|c|}
\hline \multirow[b]{2}{*}{ Species } & \multicolumn{3}{|c|}{ Devils Lake, North Dakota } & \multicolumn{3}{|c|}{ Fergus Falls, Minnesota } & \multicolumn{3}{|c|}{ Spirit Lake, Iowa } \\
\hline & $\mathrm{P}$ & D1 & D2 & $\mathrm{P}$ & D1 & D2 & $\mathrm{P}$ & D1 & D2 \\
\hline Tiger Salamander - Ambystoma tigrinum & $*$ & $*$ & $*$ & $*$ & $*$ & $*$ & $*$ & $*$ & $*$ \\
\hline American Toad - Anaxyrus americanus ${ }^{3}$ & & & & $*$ & $*$ & * & $*$ & $*$ & $*$ \\
\hline Great Plains Toad - Anaxyrus cognatus & $*$ & $*$ & $*$ & $*$ & & & $*$ & & \\
\hline Canadian Toad - Anaxyrus hemiophrys ${ }^{3}$ & $*$ & & & $*$ & $*$ & $*$ & & & \\
\hline Cope's Gray Treefrog - Hyla chrysoscelis ${ }^{1}$ & & & & $*$ & $*$ & * & $*$ & $*$ & $*$ \\
\hline Eastern Gray Treefrog - Hyla versicolor ${ }^{1}$ & & & & $*$ & $*$ & $*$ & $*$ & $*$ & $*$ \\
\hline Boreal Chorus Frog - Pseudacris maculata ${ }^{2}$ & $*$ & $*$ & $*$ & $*$ & $*$ & * & $*$ & $*$ & $*$ \\
\hline Western Chorus Frog - Pseudacris triseriata ${ }^{2}$ & & & & $*$ & $*$ & * & $*$ & $*$ & $*$ \\
\hline Northern Leopard Frog - Lithobates pipiens & $*$ & $*$ & $*$ & $*$ & $*$ & * & $*$ & $*$ & $*$ \\
\hline Wood Frog - Lithobates sylvatica & * & $*$ & $*$ & $*$ & $*$ & * & & & \\
\hline Total & 6 & 5 & 5 & 10 & 9 & 9 & 8 & 7 & 7 \\
\hline
\end{tabular}

${ }^{1}$ Species combined as Gray Treefrog

${ }^{2}$ Species combined as Chorus Frog

${ }^{3}$ Larvae of species combined as toad larvae 
to species. Discrepancies between data records were reevaluated by a third listener who made the final decision.

Aquatic funnel traps (Mushet et al. 1997) were used to capture amphibians in wetlands with $\geq 5 \mathrm{~cm}$ of water. We placed three traps in each wetland parallel with the shore halfway between the wetland center and wetland edge (i.e., wet meadow zone or mudflat edge). Each trap was placed along one of three transects set at 0,120 , and $240^{\circ}$ compass bearings radiating from the center of each wetland. Traps remained in place for $24 \mathrm{~h}$, after which captured amphibians were identified to species and developmental stage (adult or larvae) prior to their being released at the trap site.

Four observers in 2005 and three observers in 2006 conducted visual encounter surveys during all sampling events. Each survey began with an initial search of the outer edge of the wet meadow zone (the vegetative zone adjacent to the upland) of each wetland. After we searched the wet meadow zone, we then searched the remainder of the wetland. We used polarized sunglasses to enhance detection of amphibians beneath the water surface. Amphibians encountered were identified to species and developmental stage (adult or larvae). In some cases, we used small dip-nets to capture larvae for identification. Survey start and end times and maximum pool depth $(\mathrm{cm})$ were recorded during each survey. To standardize survey effort, searches were limited to 45-60 min at each wetland. Exact time depended on the visual complexity of the habitat and the number of observers (i.e. surveys of bare dirt wetlands with more observers present were surveyed for a shorter period than a well vegetated wetland with fewer observers present).

In 2006, we also surveyed the vegetation at the study wetlands. Our surveys included not only wetland plants, but also species occurring within $10 \mathrm{~m}$ of the outer most edge of the wetland. Surveys were conducted by walking within the search area until no new species were encountered. All plant species were identified and published coefficient of conservatism values for each wetland (Northern Great Plains Floristic Quality Assessment Panel 2001) were used to calculate mean coefficient of conservatism $\left(\mathrm{C}^{-}\right)$values for each site. Coefficient of conservatism is an index of how tolerant the aggregated plant community is to disturbance (Swink and Wilhelm 1994) and was used as a variable in our occupancy models.

\section{Data Analyses}

We estimated species-specific occupancy frequency $(\psi)$ and the probability of detection ( $p$ ) (MacKenzie et al. 2002) for both adult and larval amphibians using PRESENCE software (version 3.0, Hines 2006); sample sizes differed because the range of some species did not include all 3 study areas. We used single-season models for each species rather than multiseason models. We assumed: 1) there was no local colonization or extinction by a species during sampling periods, 2) each adult and larval species was correctly identified, 3) the probability of detecting each adult or larval species at one study wetland was independent of the probability of detecting the same adult or larval species at all other study wetlands, and 4) that detections were independent at a given site across visits (MacKenzie et al. 2006). We created a detection history for each species for each of the study wetlands by compiling data from all applicable survey techniques used during each site visit. For adult anurans, we utilized visual encounter surveys, aquatic funnel traps, and automated call recordings. For anuran larvae and amphibian species that do not vocalize (i.e., tiger salamanders) we only used visual encounter surveys and aquatic funnel traps.

We used a modified version of Schmidt and Pellet's (2005) two-step process to analyze detection and occupancy probabilities. In Step 1, we used an a priori approach to construct a set of candidate models that explained probability of detection. We determined if detection probability remained constant throughout our sampling period (.), varied throughout our sampling period ( $\mathrm{t}$ ), varied linearly throughout our sampling season (linear), varied linearly or quadratically with the time of day (time of day and time of day $^{2}$, respectively), or was dependent on our use of automated recorders. Since recorders sometimes failed, we were able to include the effectiveness of recorders as a separate variable to test the importance of this sampling technique in detecting adult anurans.

Unlike Schmidt and Pellet (2005) who selected the simplest model for occupancy (i.e., assuming constant occupancy over time), we selected the most complex model (i.e., the global model) because it contained all parameters potentially affecting amphibian occupancy. This allowed for the most flexibility in the fitting of our data for occupancy (D. I. MacKenzie, pers. comm.). We used Akaike's Information Criterion with a small sample size correction (AICc) to identify the most parsimonious model for detection probability (Burnham and Anderson 2002). The highest ranked detection model was then incorporated into each candidate occupancy model.

In Step 2, we used an a priori approach to develop a set of candidate models to determine if there were differences in occupancy between study sites and/or among the three landuse categories (i.e. farmed, conservation grasslands, and native prairie grasslands). Our candidate set of models included: 1) null model (i.e. no difference in occupancy between study areas and or land use), 2) study area effect, 3) land-use effect, and 4) study area and land-use effect. However, because of small sample sizes we used wetland $\overline{\mathrm{C}}$ values of each site as a proxy for land-use since land-use categories were accurately represented by continuous $\overline{\mathrm{C}}$ values (ANOVA; $\mathrm{df}=2,35, F=$ 49.96, $P<0.001$ ). Farmed wetlands had an average $\bar{C}$ value of $1.24(95 \%$ Confidence Interval $=0.637$ to 1.846$)$, whereas 
conservation and native prairie wetlands had average $\overline{\mathrm{C}}$ values of $3.25(95 \%$ Confidence Interval $=2.984$ to 3.666$)$ and 3.98 (95\% Confidence Interval $=3.727$ to 4.223 ), respectively. No overlap in confidence intervals was detected thereby increasing our confidence in the use of this proxy in analyses. Our use of this proxy, while not a reliable measure of anthropogenic disturbance of wetlands (Euliss and Mushet 2011), allowed us to avoid complete or quasi complete separation bias associated with categorical covariates and small sample size (Allison 2004).

In addition to using $\overline{\mathrm{C}}$ as a land-use proxy, we also considered inclusion of maximum pool depth in June (a covariate related to hydroperiod length). However, this proxy was positively correlated (collinear) with wetland $\overline{\mathrm{C}}$ values in both 2005 and $2006\left(P<0.001, \mathrm{R}^{2}=0.47\right.$ and $P<$ $0.001, R^{2}=0.33$, respectively). Therefore, we excluded water depth from further analysis. For the land-use proxy, we included both linear $(\overline{\mathrm{C}})$ and quadratic $\left(\overline{\mathrm{C}}^{2}\right)$ covariate effects to facilitate comparisons between our three land-use conditions. To avoid over parameterization, we minimized the candidate set of models for occupancy by focusing only on additive models (Burnham and Anderson 2002). We again ranked competing occupancy models using AICc; however, we first assessed fit of the global model using the parametric bootstrap test ( $n=1000$; MacKenzie and Bailey 2004). This method provided an estimate of over-dispersion ( $\hat{c})$, which we used to quantify lack of fit of the model to our dataset. When $\hat{c}>1$, we used $\hat{c}$ as a variance inflation factor to adjust each model's AICc value to a Quasi Akaike's Information Criterion with a small sample size correction value (QAICc) to rank competing models (Burnham and Anderson 2002). We also used $\hat{c}$ to adjust standard errors of occupancy and detection probability parameter estimates for all models with over-dispersed data sets (MacKenzie and Bailey 2004). We used AICc or QAICc differences $\left(\Delta_{i}\right)$ and AICc or QAICc weights $\left(w_{i}\right)$ for model inference (Burnham and Anderson 2002).

Because we were unable to identify a top model $\left(w_{i}>0.90\right)$ and because we used categorical covariates in our analysis, we used model averaged predictions to evaluate parameter influence on occupancy and detection probabilities (Burnham and Anderson 2002). We only evaluated parameters of models with $\Delta_{i}<2.00$. For those parameters we used only those models within the candidate set of models that contained predictive information on the parameter of interest and recalculated their $w_{i}$. We then introduced the beta coefficient estimates of each of those models with associated covariate information into a logistic regression equation (MacKenzie et al. 2002) to derive predictions based off the parameter in question (Burnham and Anderson 2002). Each prediction and its associated $\mathrm{w}_{\mathrm{i}}$ were then used to compute weighted averages of those predictions using the following equation (Burnham and Anderson 2002):

Model Average Prediction for $\widehat{\psi}$ or $\widehat{p}=\sum_{i=1}^{R} w_{i}($ Predicted $\widehat{\psi}$ or $\widehat{p})$

When both the linear and quadratic mean $\overline{\mathrm{C}}$ parameters were identified in the highest ranked models, we calculated model averaged predicted estimates for both parameters. This facilitated a comparative inference on the two differing hypotheses of land use effect on amphibian occupancy.

\section{Results}

We detected eight amphibian species at one or more of our study wetlands (Table 1). Adults of each species were detected both years. With the exception of Great Plains toad larvae in 2006, we detected larvae from each species both years. However, we were not able to model all adult and larval species we detected because: 1) we were unable to define a sampling "season" that abided by the closed population and correct identification assumptions (MacKenzie et al. 2006), 2) our sample size was too small (Weller 2008), and/or 3) we had too high or too low naïve occupancy probabilities (Wood 2007). The amphibians we were able to model included adult American toads in 2006, larval chorus frogs in 2005 and 2006, adult gray treefrogs in 2006, adult northern leopard frogs (Lithobates pipiens) in 2005 and 2006, larval northern leopard frogs in 2006, adult and larval tiger salamanders in 2005 and 2006, and larval wood frogs (Lithobates sylvatica) in 2006 (Table 2).

\section{Detection Probability}

Detection probabilities varied among species, developmental stage, sampling period, and/or year. Detection probability for both adult and larval tiger salamanders did not vary temporally ( 0.63 and 0.93 , respectively, in both 2005 and 2006). While, detection probability for larval chorus frogs also remained stable (0.81) throughout our sampling season in 2005, in 2006 chorus frog detection probability decreased from a high of 0.89 in late May to 0.69 in early June, and finally to 0.39 by late June. While remaining stable at 0.68 in 2006, in 2005 detection probability of leopard frog adults was much lower and varied temporally. Detection probability for adult leopard frogs in 2005 was 0.66 in late May, peaked at 0.84 in early June, and dropped sharply to 0.21 by late June. In contrast to the temporal trend of adults, detection probability of leopard frog larvae was lowest in late May (0.36), higher in early June (0.69), and highest in late June (0.89), the sample period when adult leopard frog detection probability was at its 
Table 2 Rankings of initial detection ( $p$ ) (Step 1) and final detection and occupancy $(\psi)($ Step 2) models using Akaike's Information Criterion with a small sample size correction (AICc) or overdispersion correction (QAICc), the models shown compose the 95\% confidence set of model weight $\left(\mathrm{w}_{i}\right)$ for each step of each amphibian modeled. $\mathrm{K}$ equals the number of parameters for each model

\begin{tabular}{llllllll}
\hline Models & $\mathrm{K}$ & $\mathrm{AIC}_{\mathrm{c}}$ & $\mathrm{QAIC}_{\mathrm{c}}$ & $\Delta \mathrm{AIC}_{\mathrm{c}}$ & $\Delta \mathrm{QAIC}_{\mathrm{c}}$ & $\mathrm{w}_{i}$ \\
\hline
\end{tabular}

American Toad (adult, 2006)

Step 1:

$\psi\left(\right.$ study site, $\left.\overline{\mathrm{C}}, \overline{\mathrm{C}}^{2}\right), p$ (recorder use)

$\psi\left(\right.$ study site, $\left.\overline{\mathrm{C}}, \overline{\mathrm{C}}^{2}\right), p($.)

$\psi\left(\right.$ study site, $\left.\overline{\mathrm{C}}, \overline{\mathrm{C}}^{2}\right), p($ linear)

Step 2:

$\psi($ study site), $p$ (recorder use)

$\psi($ study site, $\overline{\mathrm{C}}), p$ (recorder use)

$\psi(),. p()-$. Null Model

$\psi(),$.$p (recorder use)$

$\psi\left(\right.$ study site, $\left.\overline{\mathrm{C}}, \overline{\mathrm{C}}^{2}\right), p$ (recorder use)

Chorus Frog (larvae, 2005)

Step 1:

$\psi\left(\right.$ study site, $\left.\overline{\mathrm{C}}, \overline{\mathrm{C}}^{2}\right), p($.)

$\psi\left(\right.$ study site, $\left.\overline{\mathrm{C}}, \overline{\mathrm{C}}^{2}\right), p$ (time of day)

$\psi\left(\right.$ study site, $\left.\overline{\mathrm{C}}, \overline{\mathrm{C}}^{2}\right), p$ (linear)

$\psi\left(\right.$ study site, $\left.\overline{\mathrm{C}}, \overline{\mathrm{C}}^{2}\right), p\left(\right.$ time of day, time of day $\left.{ }^{2}\right)$

Step 2:

$\psi\left(\overline{\mathrm{C}}, \overline{\mathrm{C}}^{2}\right), p($.

$\psi\left(\right.$ study site, $\left.\overline{\mathrm{C}}, \overline{\mathrm{C}}^{2}\right), p($.)

$\psi(\overline{\mathrm{C}}), p($.

$\psi(),. p()-$. Null Model

$\psi($ study site, $\overline{\mathrm{C}}), p($.)

Chorus Frog (larvae, 2006)

Step 1:

$\psi\left(\right.$ study site, $\left.\overline{\mathrm{C}}, \overline{\mathrm{C}}^{2}\right), p($ linear)

$\psi\left(\right.$ study site, $\left.\overline{\mathrm{C}}, \overline{\mathrm{C}}^{2}\right), p(\mathrm{t})$

Step 2:

$\psi\left(\right.$ study site, $\left.\overline{\mathrm{C}}, \overline{\mathrm{C}}^{2}\right), p($ linear)

$\psi\left(\overline{\mathrm{C}}, \overline{\mathrm{C}}^{2}\right), p($ linear $)$

Gray Treefrog (adult, 2006)

Step 1:

$\psi\left(\right.$ study site, $\left.\overline{\mathrm{C}}, \overline{\mathrm{C}}^{2}\right), p$ (recorder use)

$\psi\left(\right.$ study site, $\left.\overline{\mathrm{C}}, \overline{\mathrm{C}}^{2}\right), p(\mathrm{t})$

$\psi\left(\right.$ study site, $\left.\overline{\mathrm{C}}, \overline{\mathrm{C}}^{2}\right), p($.)

$\psi\left(\right.$ study site, $\overline{\mathrm{C}}, \overline{\mathrm{C}}^{2}$ ), $p$ (time of day)

Step 2:

$\psi($ study site), $p$ (recorder use)

$\psi\left(\right.$ study site, $\left.\overline{\mathrm{C}}, \overline{\mathrm{C}}^{2}\right), p$ (recorder use)

$\psi($ study site, $\overline{\mathrm{C}}), p$ (recorder use)

$\psi(),$.$p (recorder use)$

Northern Leopard Frog (adult, 2005)

Step 1:

$\psi\left(\right.$ study site, $\left.\overline{\mathrm{C}}, \overline{\mathrm{C}}^{2}\right), p(\mathrm{t})$

$\psi\left(\right.$ study site, $\left.\overline{\mathrm{C}}, \overline{\mathrm{C}}^{2}\right), p($ linear)

Step 2:

$\psi($ study site, $\overline{\mathrm{C}}), p(\mathrm{t})$
72.93

76.01

5

6

102.79

103.55

83.37

85.51

86.47

88.72

54.13

54.30

55.33

56.33

57.50

46.78

47.61

48.88

49.39

49.69

7

99.25

104.11

0.00

0.74

3.08

0.16

5.13

0.06

0.00

0.38

0.83

0.25

2.10

0.13

2.61

0.10

2.90

0.09

0.00

0.60

2.14

0.21

3.10

0.13

5.36

0.04

0.00

0.32

0.17

0.30

1.21

0.18

2.21

0.11

3.37

0.06

0.00

0.58

0.76

0.40

95.15

0.00

0.81

98.53

3.39

0.15

0.00

0.48

0.91

0.31

2.89

0.11

4.05

0.06

52.80

54.82

56.02

58.85

0.00

0.60

2.02

0.22

3.22

0.12

6.04

0.03

0.00

0.91

4.86

0.08

7

94.50

0.00

0.40 
Table 2 (continued)

\begin{tabular}{|c|c|c|c|c|c|c|}
\hline Models & $\mathrm{K}$ & $\mathrm{AIC}_{\mathrm{c}}$ & $\mathrm{QAIC}_{\mathrm{c}}$ & $\Delta \mathrm{AIC}_{\mathrm{c}}$ & $\Delta \mathrm{QAIC}_{\mathrm{c}}$ & $\mathrm{w}_{i}$ \\
\hline$\psi\left(\right.$ study site, $\left.\overline{\mathrm{C}}, \overline{\mathrm{C}}^{2}\right), p(\mathrm{t})$ & 8 & 99.25 & & 0.75 & & 0.28 \\
\hline$\psi(\overline{\mathrm{C}}), p(\mathrm{t})$ & 5 & 100.53 & & 2.03 & & 0.15 \\
\hline$\psi\left(\overline{\mathrm{C}}, \overline{\mathrm{C}}^{2}\right), p(\mathrm{t})$ & 6 & 100.62 & & 2.12 & & 0.14 \\
\hline \multicolumn{7}{|l|}{ Northern Leopard Frog (adult, 2006) } \\
\hline \multicolumn{7}{|l|}{ Step 1: } \\
\hline$\psi\left(\right.$ study site, $\left.\overline{\mathrm{C}}, \overline{\mathrm{C}}^{2}\right), p()$. & 6 & 100.03 & & 0.00 & & 0.52 \\
\hline$\psi\left(\right.$ study site, $\left.\overline{\mathrm{C}}, \overline{\mathrm{C}}^{2}\right), p($ recorder use $)$ & 7 & 102.80 & & 2.77 & & 0.13 \\
\hline$\psi\left(\right.$ study site, $\left.\overline{\mathrm{C}}, \overline{\mathrm{C}}^{2}\right), p($ time of day $)$ & 7 & 103.01 & & 2.98 & & 0.12 \\
\hline$\psi\left(\right.$ study site, $\left.\overline{\mathrm{C}}, \overline{\mathrm{C}}^{2}\right), p$ (linear) & 7 & 103.10 & & 3.10 & & 0.11 \\
\hline$\psi\left(\right.$ study site, $\left., \overline{\mathrm{C}}, \overline{\mathrm{C}}^{2}\right), p(\mathrm{t})$ & 8 & 103.13 & & 3.84 & & 0.08 \\
\hline \multicolumn{7}{|l|}{ Step 2: } \\
\hline$\psi($ study site,$\overline{\mathrm{C}}), p()$. & 5 & 97.77 & & 0.00 & & 0.67 \\
\hline$\psi\left(\right.$ study site, $\left.\overline{\mathrm{C}}, \overline{\mathrm{C}}^{2}\right), p()$. & 6 & 100.03 & & 2.26 & & 0.22 \\
\hline$\psi(\overline{\mathrm{C}}), p()$. & 3 & 101.93 & & 4.16 & & 0.08 \\
\hline
\end{tabular}

Northern Leopard Frog (larvae, 2006)

Step 1:

$\psi\left(\right.$ study site, $\left.\overline{\mathrm{C}}, \overline{\mathrm{C}}^{2}\right), p($ linear)

73.50

0.00

0.47

$\psi\left(\right.$ study site, $\left.\overline{\mathrm{C}}, \overline{\mathrm{C}}^{2}\right), p(\mathrm{t})$

$\psi\left(\right.$ study site, $\left.\overline{\mathrm{C}}, \overline{\mathrm{C}}^{2}\right), p($.)

73.54

0.04

0.46

Step 2:

$\psi($ study site, $\overline{\mathrm{C}}), p$ (linear)

77.74

4.24

0.06

$\psi\left(\right.$ study site, $\left.\overline{\mathrm{C}}, \overline{\mathrm{C}}^{2}\right), p$ (linear)

72.24

0.00

0.61

73.50

0.32

$\psi($ study site), $p$ (linear)

78.59

0.03

Tiger Salamander (adult, 2005)

Step 1:

$\psi\left(\right.$ study site, $\left.\overline{\mathrm{C}}, \overline{\mathrm{C}}^{2}\right), p($.)

$\psi\left(\right.$ study site, $\left.\overline{\mathrm{C}}, \overline{\mathrm{C}}^{2}\right), p$ (time of day)

$\psi\left(\right.$ study site, $\overline{\mathrm{C}}, \overline{\mathrm{C}}^{2}$ ), $p$ (linear)

$\psi\left(\right.$ study site, $\left.\overline{\mathrm{C}}, \overline{\mathrm{C}}^{2}\right), p\left(\right.$ time of day, time of $\mathrm{day}^{2}$ )

1.26

6.35

.52

Step 2:

$\psi\left(\overline{\mathrm{C}}, \overline{\mathrm{C}}^{2}\right), p($.

$\psi(),. p()-$. Null Model

$\psi(\overline{\mathrm{C}}), p($.

$\psi\left(\right.$ study site, $\left.\overline{\mathrm{C}}, \overline{\mathrm{C}}^{2}\right), p($.)

$\psi($ study site), $p($.)

68.22

0.00

0.45

69.18

0.96

0.28

70.22

0.17

71.96

0.07

3.75

0.57

63.65

0.00

0.20

65.78

2.13

0.11

68.22

0.06

69.05

4.57

0.04

Tiger Salamander (adult, 2006)

Step 1:

$\psi\left(\right.$ study site, $\left.\overline{\mathrm{C}}, \overline{\mathrm{C}}^{2}\right), p($.)

57.04

0.00

0.35

57.39

0.35

0.30

58.58

0.16

$\psi\left(\right.$ study site, $\left.\overline{\mathrm{C}}, \overline{\mathrm{C}}^{2}\right), p$ (time of day, time of day ${ }^{2}$ )

1.55

0.16

Step 2:

$\psi\left(\overline{\mathrm{C}}, \overline{\mathrm{C}}^{2}\right), p($.

58.63

1.59

0.48

51.77

0.00

0.29

52.76

0.99

0.15

$\psi(\overline{\mathrm{C}}), p($.

54.11

2.34

0.03

Tiger Salamander (larvae, 2005)

57.04

5.27

0.54

Step 1:

$\psi\left(\right.$ study site, $\left.\overline{\mathrm{C}}, \overline{\mathrm{C}}^{2}\right), p($ linear)

58.86

0.00 
Table 2 (continued)

\begin{tabular}{|c|c|c|c|c|c|c|}
\hline Models & $\mathrm{K}$ & $\mathrm{AIC}_{\mathrm{c}}$ & $\mathrm{QAIC}_{\mathrm{c}}$ & $\Delta \mathrm{AIC}_{\mathrm{c}}$ & $\Delta \mathrm{QAIC}_{\mathrm{c}}$ & $\mathrm{w}_{i}$ \\
\hline$\psi\left(\right.$ study site, $\left.\overline{\mathrm{C}}, \overline{\mathrm{C}}^{2}\right), p(.)^{\mathrm{a}}$ & 6 & 60.47 & & 1.61 & & 0.24 \\
\hline$\psi\left(\right.$ study site, $\left.\overline{\mathrm{C}}, \overline{\mathrm{C}}^{2}\right), p(\mathrm{t})$ & 8 & 62.19 & & 3.33 & & 0.10 \\
\hline$\psi\left(\right.$ study site, $\left., \overline{\mathrm{C}}, \overline{\mathrm{C}}^{2}\right), p($ time of day) & 7 & 63.07 & & 4.21 & & 0.07 \\
\hline \multicolumn{7}{|l|}{ Step 2: } \\
\hline$\psi(\overline{\mathrm{C}}), p()$. & 3 & 55.14 & & 0.00 & & 0.54 \\
\hline$\psi\left(\overline{\mathrm{C}}, \overline{\mathrm{C}}^{2}\right), p()$. & 4 & 57.37 & & 2.23 & & 0.18 \\
\hline$\psi($ study site, $\overline{\mathrm{C}}, p()$. & 5 & 57.79 & & 2.65 & & 0.14 \\
\hline$\psi(),. p()-$. Null Model & 2 & 59.09 & & 3.95 & & 0.08 \\
\hline$\psi\left(\right.$ study site $\left., \overline{\mathrm{C}}, \overline{\mathrm{C}}^{2}\right), p()$. & 6 & 60.48 & & 5.33 & & 0.04 \\
\hline \multicolumn{7}{|l|}{ Tiger Salamander (larvae, 2006) } \\
\hline \multicolumn{7}{|l|}{ Step 1: } \\
\hline$\psi\left(\right.$ study site $\left., \overline{\mathrm{C}}, \overline{\mathrm{C}}^{2}\right), p()$. & 6 & 93.23 & & 0.00 & & 0.62 \\
\hline$\psi\left(\right.$ study site $\left., \overline{\mathrm{C}}, \overline{\mathrm{C}}^{2}\right), p($ time of day) & 7 & 96.00 & & 2.77 & & 0.16 \\
\hline$\psi\left(\right.$ study site $\left., \mathrm{C}^{-}, \mathrm{C}^{-2}\right), p($ linear $)$ & 7 & 96.17 & & 2.94 & & 0.14 \\
\hline$\psi\left(\right.$ study site, $\left.\mathrm{C}^{-}, \mathrm{C}^{-2}\right), p\left(\right.$ time of day, time of day $\left.{ }^{2}\right)$ & 8 & 98.22 & & 5.00 & & 0.05 \\
\hline \multicolumn{7}{|l|}{ Step 2: } \\
\hline$\psi\left(\mathrm{C}^{-}\right), p()$. & 3 & 87.11 & & 0.00 & & 0.64 \\
\hline$\psi\left(\mathrm{C}^{-}, \mathrm{C}^{-2}\right), p()$. & 4 & 89.45 & & 2.34 & & 0.20 \\
\hline$\psi\left(\right.$ study site, $\left.\mathrm{C}^{-}\right), p()$. & 5 & 90.43 & & 3.32 & & 0.12 \\
\hline \multicolumn{7}{|l|}{ Wood Frog (larvae, 2006) } \\
\hline \multicolumn{7}{|l|}{ Step 1: } \\
\hline$\psi\left(\right.$ study site $\left., \mathrm{C}^{-}, \mathrm{C}^{-2}\right), p($ linear $)$ & 6 & 62.76 & & 0.00 & & 0.71 \\
\hline$\psi\left(\right.$ study site $\left., \mathrm{C}^{-}, \mathrm{C}^{-2}\right), p()$. & 5 & 65.86 & & 3.10 & & 0.15 \\
\hline$\psi\left(\right.$ study site $\left., \mathrm{C}^{-}, \mathrm{C}^{-2}\right), p(\mathrm{t})$ & 7 & 66.56 & & 3.80 & & 0.11 \\
\hline \multicolumn{7}{|l|}{ Step 2: } \\
\hline$\psi\left(\mathrm{C}^{-}\right), p($ linear $)$ & 4 & 58.64 & & 0.00 & & 0.35 \\
\hline$\psi\left(\overline{\mathrm{C}}, \overline{\mathrm{C}}^{2}\right), p($ linear $)$ & 5 & 59.17 & & 0.54 & & 0.27 \\
\hline$\psi(),$.$p (linear)$ & 3 & 60.03 & & 1.39 & & 0.18 \\
\hline$\psi($ study site,$\overline{\mathrm{C}}), p($ linear $)$ & 5 & 61.67 & & 3.04 & & 0.08 \\
\hline$\psi($ study site $), p$ (linear) & 4 & 62.25 & & 3.61 & & 0.06 \\
\hline$\psi\left(\right.$ study site, $\left.\overline{\mathrm{C}}, \overline{\mathrm{C}}^{2}\right), p$ (linear) & 6 & 62.76 & & 4.13 & & 0.04 \\
\hline
\end{tabular}

${ }^{\mathrm{a}}$ The second best fitting was chosen for further Occupancy $(\psi)$ analysis because the best fitting model failed to converge completely

lowest. Detection probabilities for both American toads and gray treefrogs were greatly improved through the use of recorders. Detection probability for American toads was 0.55 when recorders were used in conjunction with visual encounter surveys and trapping surveys, compared to 0.13 when they were not used. Gray treefrogs were only detected through the use of recorders (0.50).

\section{Occupancy by Region}

Occupancy probability varied among the three regions. In 2005, larval chorus frogs had the lowest probability of occupancy (0.36) in ND, while $\mathrm{MN}$ was higher (0.62) and IA was highest (0.79). In 2006, chorus frog occupancy probability increased at all three sites over
2005 levels with ND (0.85) exceeding MN (0.70); larval chorus frog occupancy probability remained highest in IA at 0.99. In 2005, adult leopard frog occupancy probability was lowest in ND (0.26), higher in IA (0.47) and highest in MN (0.92). In 2006, occupancy probability for this species dropped even lower in ND (0.05). IA and $\mathrm{MN}$ had similar occupancy probabilities for adult leopard frogs in 2006 (0.72 and 0.71, respectively). For northern leopard frog larvae in 2006, occupancy probability was zero in ND, 0.30 in $\mathrm{MN}$, and 0.56 in IA. In 2006, occupancy probability for American toad adults in $\mathrm{MN}$ was lower $(0.28)$ than in IA (0.83). This difference in occupancy probability was reversed for adult gray treefrogs with $\mathrm{MN}$ having the highest occupancy probability $(0.87)$ compared to IA (0.13). 
Occupancy by Land Use

Amphibian occupancy in the three land use categories also varied by species, life stage, and year. While trends varied slightly depending on whether a linear or quadratic relationship to $\overline{\mathrm{C}}$ was used (Fig. 2), we report only linear relationships when overall conclusions are similar and note quadratic relationships when they differ. In 2005, the linear relationship of occupancy probability to $\overline{\mathrm{C}}$ for larval chorus frogs was 0.26 in farmed wetlands compared to 0.45 in conservation and 0.53 in native prairie wetlands (Fig. 2). In 2006, chorus frog larvae occupancy probability decreased to 0.21 in farmed wetlands while increasing to 0.55 and 0.63 in conservation and native prairie wetlands, respectively (Fig. 2). However, in both 2005 and 2006, the quadratic relationship showed lower occupancy for larval chorus frogs in native prairie wetlands than in conservation wetlands (Fig. 2). Adult northern leopard frog occupancy probability was 0.20 in farmed wetlands, 0.60 in conservation wetlands, and 0.72 in native prairie wetlands (Fig. 2). In 2006, adult leopard frog occupancy probability was only 0.07 in farmed wetlands, remained at 0.60 in conservation wetlands, and was 0.77 in native prairie wetlands (Fig. 2). While lower overall compared to adults, occupancy probability of northern leopard frog larvae followed the same trend of being lowest in farmed wetlands (0.05), higher in conservation wetlands $(0.35)$, and highest in native prairie wetlands (0.48).

Similar to leopard frog larvae, both adult and larval tiger salamanders had relatively low occupancy probabilities across all sites. In 2005, occupancy probability for adult tiger salamander in farmed wetlands was 0.17 compared to 0.21 in conservation wetlands and 0.23 in native prairie wetlands (Fig. 2). Trends held in 2006 with adult tiger salamander occupancy probabilities being $0.21,0.26$, and 0.27 in farmed, conservation, and native prairie wetlands, respectively (Fig. 2). Similar to larval chorus frogs, adult tiger salamanders showed a decline in occupancy probability between conservation and native prairie wetlands when a quadratic relationship was assumed (Fig. 2). Occupancy probabilities for tiger salamander larvae were essentially identical between years with farmed wetlands being the lowest (0.07 each year), restored wetlands having higher occupancy (0.26 each year), and native prairie wetlands having the highest occupancy probabilities $(0.39$ and 0.38 in 2005 and 2006, respectively). Occupancy probabilities for adult wood frogs in 2006 varied from 0.22 in farmed wetlands, to 0.55 in native prairie habitats. Conservation habitats once again were intermediary at 0.45 (Fig. 2) unless a quadratic relationship was used, in which case occupancy probabilities of conservation wetlands and native prairie wetlands were similar (Fig. 2). Continuing the overall trend, occupancy probability of American toad adults was lowest in farmed habitats (0.44), intermediate in conservation habitats $(0.56)$, and highest in native prairie wetlands (0.60) (Fig. 2).

\section{Discussion}

Our data suggest that seasonal wetlands within CRP and WRP conservation lands were more frequently occupied by all species and life stages of the amphibian species we were able to model. Additionally, all species and life stages more frequently occupied wetlands in native prairie than wetlands in conservation grasslands when a linear relationship to land use was assumed. However, under a quadratic relationship, larval chorus frogs and adult tiger salamanders occupied conservation wetlands more frequently than native prairie wetlands and wood frogs occupied the two land-use treatments at similar frequencies. For northern leopard frogs, tiger salamanders, and wood frogs, which have extended larval development periods, higher occupancy probabilities in conservation and native prairie wetlands may be related to the longer, more stable hydroperiods in these wetlands relative to those of farmed wetlands (Euliss and Mushet 1996). Thus, while farmed wetlands can have deeper water at times than native wetlands, they also dry more quickly. Additionally, the filling of wetland basins with sediments in cropland landscapes can reduce hydroperiods of farmed wetlands (Gleason and Euliss 1998). Wetland hydroperiods may also be altered if non-native perennials become established in surrounding uplands (van der Kamp et al. 1999). Native prairie vegetation typically transpires less water from the landscape (Humphrey 1959), thus, the hydroperiod of conservation wetlands is often shorter than that of native prairie wetlands. High occupancy of chorus frog larvae in conservation wetlands (under a quadratic relationship to land-use) may reflect a need for shorter hydroperiods that facilitate successful reproduction by lowering competition with other amphibian species and eliminating potential predators such as fish, invertebrates, or tiger salamanders (Babbitt et al. 2003).

Occupancy of wetlands by adult gray treefrogs did not differ among land use types in 2006, and although we detected differences in occupancy of adult American toads in 2006 and adult tiger salamander in 2005 and 2006, the increases in occupancy were moderate as land-use shifted from farmed to conservation to native prairie. The similar patterns of occupancy of these species among wetlands in the different land use categories may be a reflection of their requirements; all three species are habitat generalists (Oldfield and Moriarty 1994). We did not detect larval tiger salamanders in farmed wetlands, which may indicate a difference in habitat quality among the three land use types. Unfortunately, we 
Adult American Toad, 2006

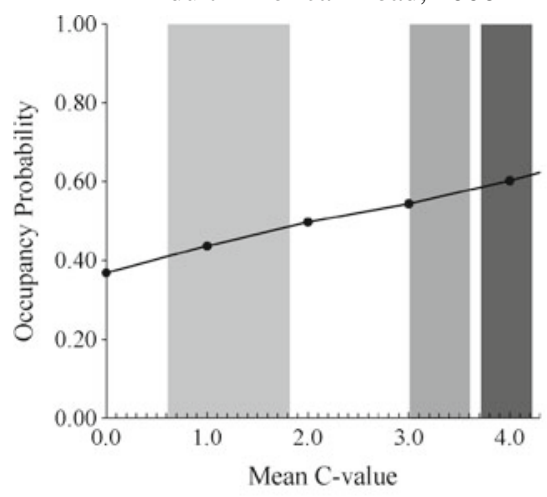

Adult Northern Leopard Frog, 2005

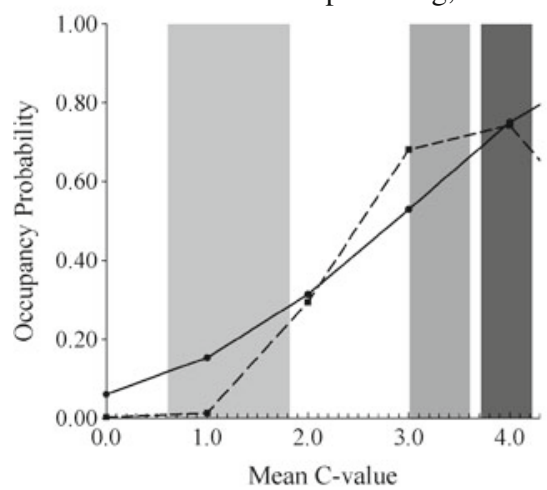

Adult Tiger Salamander, 2005


Larval Chorus Frog, 2005



Adult Northern Leopard Frog, 2006

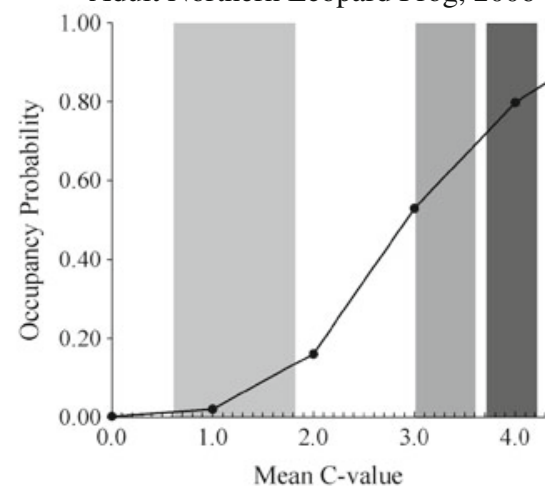

Adult Tiger Salamander, 2006
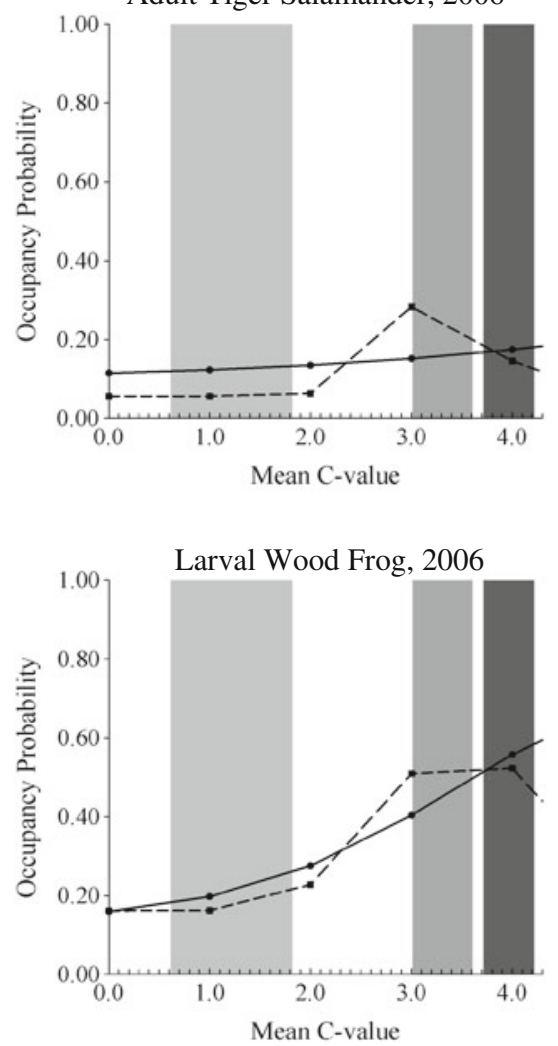

Larval Chorus Frog, 2006

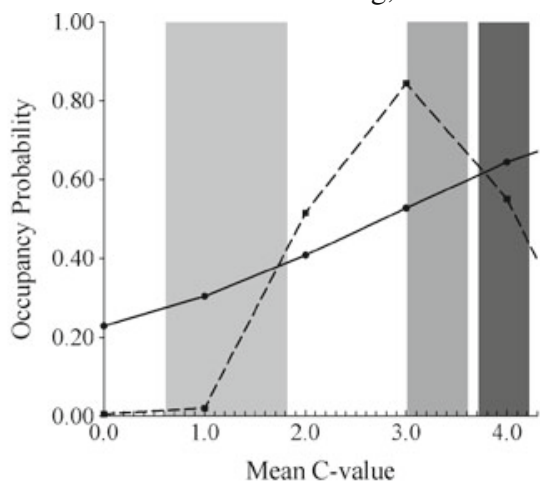

Larval Northern Leopard Frog, 2006

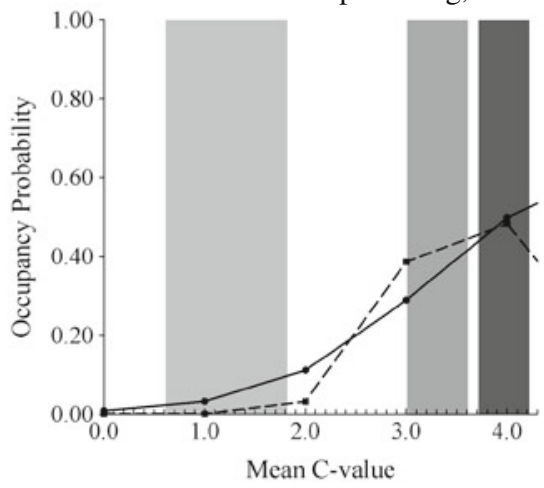

Larval Tiger Salamander, 2005




Fig. 2 Model averaged predictions of land-use effects quantified using our linear (plant; solid line, round marker) and/or quadratic (plant2; dashed line, square maker) $\overline{\mathrm{C}}$ proxy (shading represents the $95 \%$ confidence interval of each wetland land-use category's mean) to describe amphibian occupancy probabilities at farmed (light shading), conservation (medium shading), and native prairie (dark shading) seasonal wetlands located in the Prairie Pothole Region's Glaciated Plain for the summers of 2005 and 2006

were unable to identify larvae of the American toad and could not model gray treefrog larvae occupancy; therefore, we do not know whether farmed wetlands provide adequate conditions for successful reproduction of these species. Nevertheless, American toads and gray treefrogs require hydroperiods longer than 6-8 weeks for metamorphosis (Oldfield and Moriarty 1994) and only a single farmed wetland had a hydroperiod greater than 6 weeks. In the case of tiger salamanders, the adults were certainly not utilizing farmed wetlands for reproduction. Clearly, farmed wetlands would expose amphibians to the negative impacts of agrichemicals and mechanical disturbance, which both limit reproductive success and survival (Knutson et al. 1999, Relyea 2005, Hayes et al. 2006).

We explicitly accounted for bias associated with detection probabilities in our occupancy estimates (Tyre et al. 2003; MacKenzie et al. 2006) to ensure that we depicted effects of land use supported under the two conservation programs on amphibian occupancy of seasonal wetlands in the PPR. Unfortunately, we were limited in our analysis of several species due to low sample size and timeliness of surveys. These factors should be carefully considered in future studies. In our analyses, the differences in detection we found between species, life stage and years likely reflect the influence precipitation and temperature has on each species breeding phenology and the emergence of their larvae. Precipitation between the 2 years was very different; 2005 was wet and 2006 was dry (National Climate Data Center 2011). It is apparent that many factors affect the composition of prairie amphibian communities and that environmental factors influence individual species differently. Thus, it is unlikely that a generic set of environmental conditions can be identified that will benefit all of the species encountered in our study. The interplay between inter-annual climate and habitats provided by conservation programs may provide suitable conditions for the amphibian species at various times over the natural climate cycle. However, it is unclear whether favorable conditions would occur frequently enough to sustain populations of interest. To provide information for improving the amphibian conservation in the PPR, a longer term perspective is needed to better understand the synergy between climate and conservation programs. Additionally, a primary limiting factor in our analyses was sample size which limited our ability to model all species and life stages.

\section{Conclusions}

Extensive loss of wetland and upland habitats has negatively impacted amphibian communities in the PPR (Knutson et al. 1999). Most climate forecast models suggest even greater variation in seasonal and inter-annual climate precipitation patterns in the future, thus exacerbating impacts to amphibians (Field et al. 2007). Drier conditions in a region already greatly impacted by habitat fragmentation and extensive wetland losses will likely have negative impacts on many amphibian species inhabiting the PPR. Our research suggests that, while not equal to that of native prairie wetlands, the two conservation programs considered here, CRP and WRP, do provide habitat for many amphibian species and help reconnect fragmented amphibian habitats.

Acknowledgments We thank Larissa Bailey, Diane Larson, Kyle Zimmer, and two anonymous reviewers for providing comments on earlier drafts of this manuscript. Any use of trade, product, or firm names is for descriptive purposes only and does not imply endorsement by the U.S. Government. All work was conducted under a study plan reviewed and approved by the USGS Northern Prairie Wildlife Research Center's Animal Care and Use Committee.

Open Access This article is distributed under the terms of the Creative Commons Attribution Noncommercial License which permits any noncommercial use, distribution, and reproduction in any medium, provided the original author(s) and source are credited.

\section{References}

Alford RA, Dixon PM, Pechmann JHK (2001) Global amphibian population declines. Nature 414:449-500

Allison P (2004) Convergence problems in logistic regression. In: Altman M, Gill J, McDonald PM (eds) Numerical issues in statistical computing for the social scientist. John Wiley \& Sons Inc, Hoboken

Amphibian Research and Monitoring Initiative. (2007). ARMI national atlas for amphibian distributions, Anura. 2007. United States Geological Survey, Patuxent Wildlife Research Center, Laurel, Maryland http://www.pwrc.usgs.gov/armiatlas/order.cfm?recordID=Anura (accessed August 28, 2007)

Babbitt KJ, Baber MJ, Tarr TL (2003) Patterns of larval amphibian distribution along a wetland hydroperiod gradient. Canadian Journal of Zoology 81:1539-1552

Bluemle JP (2000) The face of North Dakota. 3rd edition. Dakota Geological Survey Educational, Series 26, Bismarck

Bowers DG (1998) Anuran survey methods, distribution, and landscapepattern relationships in the North Dakota Prairie Pothole Region. Master's Thesis. Department of Fisheries, Wildlife, and Conservation Biology. University of Minnesota, Minneapolis

Burnham KP, Anderson DR (2002) Model selection and multimodal inference: A practical information-theoretic approach, 2nd edn. Springer, New York

Conant R, Collins JT (1998) A field guide to reptiles and amphibians of eastern and central North America, 3rd edn. Houghton Mifflin Company, Boston and New York

Dahl TE (1990) Wetlands: losses in the United States 1780's to 1980's. U.S. Fish and Wildlife Service Publication, FWS/OBS-79/31 
Euliss NH Jr, Mushet DM (2011) A multi-year comparison of IPCI scores for prairie pothole wetlands: implications of temporal and spatial variation. Wetlands $713-723$

Euliss NH Jr, Mushet DM (1996) Water-level fluctuation in wetlands as a function of landscape condition in the prairie pothole region. Wetlands 16:587-593

Euliss NH Jr, Gleason RA, Olness A, McDougal RL, Murkin HR, Robarts RD, Bourbonniere RA, Warner BG (2006) North American prairie wetlands are important nonforested land-based carbon storage sites. Science of the Total Environment 361:179-188

Field CB, Mortsch LD, Brklacich M, Forbes DL, Kovacs P, Patz JA, Running SW, Scott MJ (2007) North America. In: Parry ML, Canziani OF, Palutikof JP, van der Linden PJ, Hanson CE (eds) Climate Change 2007: Impacts, adaptation and vulnerability. Contribution of Working Group II to the Fourth Assessment Report of the Intergovernmental Panel on Climate Change. Cambridge University Press, Cambridge, pp 617-652

Fischer TD, Backlun DC, Higgins KF, Naugle DE (1999) Field guide to South Dakota amphibians. SDAES Bulletin 733. South Dakota State University, Brookings

Gleason RA, Euliss NH Jr (1998) Sedimentation of prairie wetlands. Great Plains Research 8:97-112

Gleason RA, Laubhan MK, Euliss NH Jr (eds) (2008) Ecosystem services derived from wetland conservation practices in the United States Prairie Pothole Region with an emphasis on the U.S. Department of Agriculture Conservation Reserve and Wetlands Reserve Programs: U.S. Geological Professional Paper 1745, p 58

Halliday TR (2006) Amphibians. In: Sutherland WJ (ed) Ecological census techniques: A handbook. Cambridge University Press, Cambridge, pp 278-297

Hayes TB, Stuart AA, Mendoza M, Collins A, Noriega N, Vonk A, Johnston G, Liu R, Kpodzo D (2006) Characterization of Atrazine-induced gonadal malformations in African Clawed Frogs (Xenopus laevis) and comparisons with effects of an androgen antagonist (Cyproterone Acetate) and exogenous estrogen (17 $\beta$-Estradiol): support for the demasculinization/ feminization hypothesis. Environmental Health Perspectives 114:134-141

Heyer WR, Donnelly MA, McDiarmid RW, Hayek LC, Foster MS (1994) Measuring and monitoring biological diversity. Standard methods for amphibians. Smithsonian Institution Press, Washington, DC

Hines J (2006) PRESENCE version 2.0. United States Geological Survey, Patuxent Wildlife Research Center, Laurel

Houghton JT, Ding Y, Griggs DJ, Noguer M, van der Linden PJ, Xiaosu D (eds) (2001) Climate Change 2004: The scientific basis. Contribution of working group I to the third assessment report of the intergovernmental panel on climate change. Cambridge University Press, Cambridge

Houlahan JE, Finlay CS, Schmidt BR, Meyer AH, Kuzmin SL (2000) Quantitative evidence for global amphibian population declines. Nature 404:752-755

Humphrey RR (1959) Forage and water. Journal of Range Management 12:164-170

Kantrud HA, Newton WE (1996) A test of vegetation-related indicators of wetland quality in the prairie pothole region. Journal of Aquatic Ecosystem Health 5:177-191

Knutson GA, Euliss NH Jr (2001) Wetland restoration in the prairie pothole region of North America: a literature review. Biological Science Report, USGS/BRD/BSR-2001-0006, Reston

Knutson MG, Sauer JR, Olsen DA, Mossman MJ, Hemesath LM, Lannoo MJ (1999) Effects of landscape composition and wetland fragmentation on frog and toad abundance and species richness in Iowa and Wisconsin, USA. Conservation Biology 13:1437-1446

Lannoo MJ (1998) Status and conservation of Midwestern amphibians. University of Iowa Press, Iowa City

Lannoo MJ, Lang K, Waltz T, Phillips GS (1994) An altered amphibian assemblage: Dickinson County, Iowa, 70 years after Frank Blanchard's Survey. The American Midland Naturalist 131:311-319

Lehtinen RM, Galatowitsch SM, Tester JR (1999) Consequences of habitat loss and fragmentation for wetland amphibian assemblages. Wetlands 19:1-12

MacKenzie DI, Bailey LL (2004) Assessing the fit of site occupancy models. Journal of Agricultural, Biological, and Environmental Statistics 9:300-318

MacKenzie DI, Nichols JD, Lachman GD, Droege S, Royle JA, Langtimm CA (2002) Estimating site occupancy rates when detection probabilities are less than one. Ecology 83:2248-2255

MacKenzie DI, Nichols JD, Royle JA, Pollock KH, Bailey LL, Hines JE (2006) Occupancy estimation and modeling: inferring patterns and dynamics of species occurrence. Elsevier Academic Press, Burlington

Mushet DM, Euliss NH Jr, Hanson BH, Zodrow SG (1997) A funnel trap for sampling salamanders in wetlands. Herpetological Review 28:132-133

National Climate Data Center. (2011). Historical Palmer Drought Indices. http://www.ncdc.noaa.gov/temp-and-precip/drought/historicalpalmers.php (accessed 06 December 2011).

Northern Great Plains Floristic Quality Assessment Panel. (2001). Coefficients of conservatism for the vascular flora of the Dakotas and adjacent grasslands: U.S. Geological Survey, Biological Resources Division, Information and Technology Report USGS/ BRD/ITR-2001-0001, p 32.

Oldfield B, Moriarty JJ (1994) Amphibians and reptiles native to Minnesota. University of Minnesota Press, Minneapolis

Pechmann JHK, Estes RA, Scott DE, Whitefield Gibbons J (2001) Amphibian colonization and use of ponds created for trial mitigation of wetland loss. Wetlands 21:93-111

Relyea RA (2005) The lethal impacts of Roundup on aquatic and terrestrial amphibians. Ecological Applications 15:1118-1124

Schmidt BR, Pellet J (2005) Relative importance of population processes and habitat characteristics in determining site occupancy of two anurans. Journal of Wildlife Management 69:884 893

Sodhi NS, Bickford D, Diesmos AC, Lee TM, Koh LP, Brook BW, Sekercioglu CH, Bradshaw CJA (2008) Measuring the meltdown: drivers of global amphibian extinction and decline. PLoS One $3: 1-8$

Stewart RE, Kantrud HA (1971) Classification of natural ponds and lakes in the glaciated prairie region. U.S. Fish and Wildlife Service, U.S. Government Printing Office, Washington

Swink F, Wilhelm G (1994) Plants of the Chicago Region, 4th edn. Indiana Academy of Science, Indianapolis

Tao F, Yokozawa M, Hayashi Y, Lin E (2003) Terrestrial water cycle and the impact of climate change. Ambio 32:295-301

Tiner RW Jr (1984) Wetlands of the United States: Current status and recent trends. U.S. Fish and Wildlife Service, U.S. Government Printing Office, Washington

Tyre AJ, Tenhumber B, Field SA, Niejalke D, Parris K, Possingham HP (2003) Improving precision and reducing bias in biological surveys: estimating false-negative error rates. Ecological Applications 13:1790-1801 
van der Kamp G, Stolte WJ, Clark RG (1999) Drying out of small prairie wetlands after conversion of their catchments from cultivation to permanent brome grass. Hydrological Sciences 44:387-397

Weller TJ (2008) Using occupancy estimation to assess the effectiveness of a regional multiple-species conservation plan: bats in the Pacific Northwest. Biological Conservation 141:2279-2289

Winter TC, Rosenberry DO (1998) Hydrology of prairie pothole wetlands during drought and deluge: a 17-year study of the
Cottonwood Lake wetland complex in North Dakota in the perspective of longer term measured and proxy hydrological records. Climatic Change 40:189-209

Wood EM (2007) Occupancy models of focal bird species in Central Sierra Nevada Foothill Woodlands, California. Master's Thesis. Department of Wildlife, Humboldt State University, Arcata

Zedler JB (1996) Ecological issues in wetland mitigation: an introduction to the forum. Ecological Applications 6:33-37 